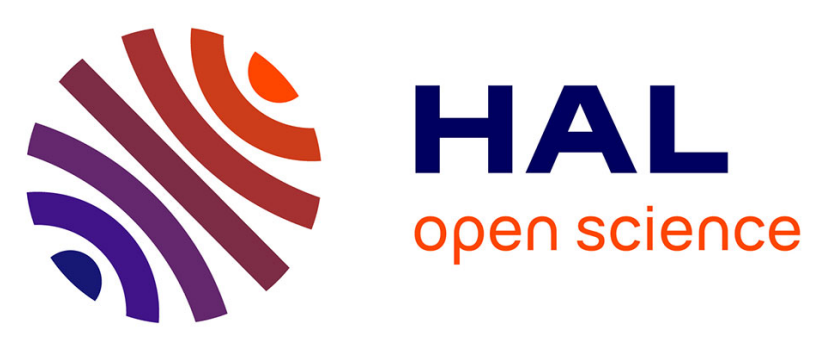

\title{
Iodine local environment in high pressure borosilicate glasses: An X-ray photoelectron spectroscopy and X-ray absorption spectroscopy investigation
}

Yann Morizet, Valentin Jolivet, Nicolas Trcera, Tomo Suzuki-Muresan, Jonathan Hamon

\section{To cite this version:}

Yann Morizet, Valentin Jolivet, Nicolas Trcera, Tomo Suzuki-Muresan, Jonathan Hamon. Iodine local environment in high pressure borosilicate glasses: An X-ray photoelectron spectroscopy and X-ray absorption spectroscopy investigation. Journal of Nuclear Materials, 2021, 553, pp.153050. 10.1016/j.jnucmat.2021.153050 . hal-03238521

\section{HAL Id: hal-03238521 \\ https://hal.science/hal-03238521}

Submitted on 7 Oct 2021

HAL is a multi-disciplinary open access archive for the deposit and dissemination of scientific research documents, whether they are published or not. The documents may come from teaching and research institutions in France or abroad, or from public or private research centers.
L'archive ouverte pluridisciplinaire HAL, est destinée au dépôt et à la diffusion de documents scientifiques de niveau recherche, publiés ou non, émanant des établissements d'enseignement et de recherche français ou étrangers, des laboratoires publics ou privés. 
IODINE LOCAL ENVIRONMENT IN HIGH PRESSURE BOROSILICATE

GLASSES: AN X-RAY PHOTOELECTRON SPECTROSCOPY AND X-RAY

ABSORPTION SPECTROSCOPY INVESTIGATION

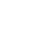

Yann MORIZET ${ }^{1,2 *}$, Valentin JOLIVET ${ }^{1,2,3}$, Nicolas TRCERA ${ }^{4}$, Tomo SUZUKI(1) MURESAN $^{3}$, Jonathan HAMON ${ }^{1}$

${ }^{1}$ Institut des Matériaux Jean Rouxel (IMN), Université de Nantes, UMR CNRS 6502, 2 rue de la Houssinière, BP32229, 44322 Nantes Cedex 3, France

\footnotetext{
${ }^{2}$ Université de Nantes, Nantes Atlantique Universités, Laboratoire de Planétologie et
} Géodynamique de Nantes (LPGN), UMR CNRS 6112, 2 rue de la Houssinière, 44322 Nantes

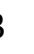
Cedex, France
${ }^{3}$ SUBATECH (IMT Atlantique, CNRS/IN2P3, Université de Nantes), BP 20722, 44307 Nantes Cedex 3, France

${ }^{4}$ Synchrotron SOLEIL, L’Orme des Merisiers, Saint Aubin, BP 48, F-91192 Gif-sur-Yvette Cedex, France 
$23 *$ Corresponding author: Yann Morizet

24 Postal address:

25 Laboratoire de Planétologie et Géodynamique (LPG), UMR-CNRS 6112, Université de 26 Nantes.

272 rue de la Houssinière, 44322 Nantes Cedex (FRANCE)

28 phone: $+33(0) 251125491$

29 fax: $+33(0) 251125268$

$30 *$ E-mail: yann.morizet@ univ-nantes.fr 


\section{Keywords}

33

Nuclear waste glasses, Iodine dissolution mechanism, X-ray Absorption Spectroscopy, X-ray Photoelectron Spectroscopy

\section{Abstract}

The ${ }^{129}$ I radioactive isotope is a by-product of nuclear plants activity. Owing to its strong volatility, there is currently no ideal protocol to immobilize ${ }^{129} \mathrm{I}$ in nuclear waste borosilicate glasses. Recently, we have proposed the use of high-pressure syntheses to dissolve iodine in various glass compositions; however, I speciation and dissolution mechanism could not be determined.

We have adopted an approach combining X-ray Photoelectron Spectroscopy (XPS) and X-ray Absorption Spectroscopy (XAS) methods to determine I speciation and molecular environment in glasses containing from 0.5 to $2.5 \mathrm{~mol} . \%$ I. The XPS spectra reveal that I is mostly dissolved as iodide $\left(>85 \% \mathrm{I}^{-}\right)$with a small proportion of elemental iodine $\left(<15 \% \mathrm{I}^{0}\right)$ and the absence of iodate species $\left(\mathrm{I}^{5+}\right)$. For borosilicate glasses, the XAS results and subsequent spectrum simulations suggested that $\mathrm{Na}$ and $\mathrm{Ca}$ are involved in the $\mathrm{I}^{-}$vicinity with averaged derived coordination number $(\mathrm{CN})$ of 3.6 and 2.0 and bond length to the nearest neighbour $\left(\mathrm{r}_{\mathrm{X}-\mathrm{I}}\right) 2.98$ and $2.85 \AA$, respectively. These results suggest that the coexistence of both $\mathrm{I}^{-}$and $\mathrm{I}^{5+}$ species is not requested for electric neutrality but instead, we explain the I speciation by the possible interplay with oxygen species from the borosilicate matrix. In addition, the results imply that the borosilicate network is affected by the I dissolution. 


\section{Introduction}

Among the many radioactive elements produced by anthropic nuclear activities, iodine (I) is one important element representing a serious glitch in the effort for immobilizing radioactive waste. One particular isotope $\left({ }^{129} \mathrm{I}\right)$ requires a special attention because of 1) its long half-life (>15 Ma) and 2) its high mobility and volatility in environment. In particular, the high I concentrations in surface water and atmosphere in industrial countries [1,2] is a health issue considering that I can easily integrate the food chain and fix into living organisms $[3,4]$.

Therefore, there is a need for a solution able to immobilize durably this isotope collected from nuclear waste.

In a recent review, Riley et al. [5] provide an exhaustive view of the different methods used to immobilize radioactive I in solid matrices. Either crystalline materials (e.g. [4,6-8]) or nuclear waste glasses (e.g. [9-11]) could be used, however, it appears that there is currently no ideal solution allowing the immobilization of radioactive $\mathrm{I}$ in a permanent and safe manner. For instance, classical melting devices operating at ambient pressure do not allow the I retention in significant concentrations in vitrified matrix [12]. At best, under ambient pressure conditions a concentration $<0.7 \mathrm{~mol} . \%$ I can be retained in borosilicate glasses as shown in previous works [9-11]. Riley et al. [10] reached almost 0.5 mol.\% I in borosilicate glasses using sealed ampoules (i.e. inside pressure above ambient pressure).

One potential solution to circumvent the strong I volatility during glass melting is to consider the I conditioning in borosilicate glass matrix under extreme conditions: high-pressure. Recent investigations [13-15] suggest that I solubility dramatically increases as the confinement pressure increases. For instance, Jolivet et al. [15] reached I solubility up to 2.5 mol.\% in nuclear waste glass compositions held at 1.5 GPa pressure. Cicconi et al. [14] dissolved $\sim 4$ mol.\% I in $\mathrm{B}_{2} \mathrm{O}_{3}$-rich glass compositions held at pressure of $150 \mathrm{MPa}$; however, 
their investigated compositions ( $\sim 60$ wt. $\left.\% \mathrm{~B}_{2} \mathrm{O}_{3}\right)$ were less relevant for the I immobilization in nuclear waste matrices. A comparable behaviour was also observed as a function of pressure for I in boron-free silicate glasses compositions with applications to Earth Sciences [16,17]. Leroy et al. [17] showed that I solubility can reach up to $1.5 \mathrm{~mol} . \%$ in $\mathrm{Si}$-poor $\mathrm{H}_{2} \mathrm{O}$ rich silicate glasses synthesised at $3.5 \mathrm{GPa}$.

One critical aspect is to clarify the I dissolution mechanism into the glass structure. Previous works [10] proposed a generic equation for I dissolution in borosilicate glasses:
$3 I_{2}^{f l}+3 \mathrm{Na}_{2} \mathrm{O}^{m} \rightarrow 5 \mathrm{NaI}^{m}+\mathrm{NaIO}_{3}^{m}$
Eq. 1

In this reaction, a diiodine molecule $\left(\mathrm{I}_{2}\right)$ from the fluid phase interacts with the $\mathrm{Na}^{+}$cations to form iodide $(\mathrm{NaI})$ and iodate $\left(\mathrm{NaIO}_{3}\right)$ within the glass. In the proposed mechanism, $\mathrm{Na}$ is a charge compensating cation to the $\mathrm{BO}_{4}$ units within the structure [18-20]. Hence, removing network modifying $\mathrm{Na}^{+}$is likely to induce the interconversion of $\mathrm{BO}_{4}$ to $\mathrm{BO}_{3}$ units in order to compensate the excess negative charges. However, the question remains debated, especially as this mechanism is greatly function of the bulk chemical composition [18] and possibly influenced by the intensive conditions for I-bearing glass synthesis. There is the coexistence of different I oxidation states in Eq. 1: -1 in $\mathrm{NaI}$ and +5 in $\mathrm{NaIO}_{3}$. In other words, the structural analysis of I-bearing glass samples should reveal the presence of both $\mathrm{I}^{-}$and $\mathrm{I}^{5+}$ species in order to satisfy the electrical charge neutrality.

Eq. 1 has been established based on XAS results [10] and to some extent, Raman spectroscopic results [13]. The XAS (both X-ray Absorption Near-Edge Structure, XANES; and Extended X-ray Absorption Fine Structure, EXAFS) is of particular interest as it probes the local environment for a given element. It has been successfully applied for the investigation of I local environment in various materials at both the $\mathrm{K}$ - and L-edges: crystalline [4,21-23]; organic [24-26]; solution [27] and glass [9-11,14,28-30]. 
To the specific case of borosilicate glasses, the study of McKeown et al. [11] is a landmark work. In a series of various borosilicate glasses typical of nuclear waste application, they determined the local environment of dissolved I (up to 0.66 mol.\%) using K-edge XAS measurements at 33,169 eV. They applied the fingerprinting method (with crystalline standards) to investigate the I K-edge XANES spectra and modelled the I K-edge EXAFS spectra. Their results demonstrate that I dissolves in borosilicate glasses as I' with a next nearest neighbour at a distance of $\sim 3.04 \AA$. They suggest that the next nearest charge compensating cation is $\mathrm{Na}^{+}$and based on the EXAFS treatment that the coordination number for $\mathrm{I}^{-}$is $\sim 4$. These results apply to borosilicate glasses synthesised at ambient pressure. The effect of pressure is known to induce bond length and coordination changes (e.g. [31-34]); therefore, the results obtained by McKeown et al. [11] may not apply to the case of borosilicate glasses synthesised under high-pressure conditions.

In the present work, we have investigated the I local environment using $\mathrm{L}_{3}$-edge XAS (both XANES and EXAFS). We have studied a series of borosilicate glasses synthesised under high-pressure conditions (0.5-1.5 GPa) and reported in the work of Jolivet et al. [15]. In addition, one sample having Na-free composition was also investigated for determining the local environment around iodine atoms in the case of Ca surrounding. The range of I content in the studied glasses is 0.5 to $2.5 \mathrm{~mol} \%$. The I local environment was determined using fingerprinting method for the XANES part and modelling of the EXAFS part using standard crystalline structure. Based on these results and previous literature data, we propose a discussion on the I dissolution mechanisms in borosilicate glasses synthesised under pressure conditions.

\section{Analytical methods}

\subsection{Starting samples}


Several types of glass composition were used for this work. The samples as well as the synthesis method are fully described in Jolivet et al. [15]. The investigated compositions are two aluminoborosilicate glasses, International Simple Glass (ISG, [35]) and a Low Activity Waste (LAW) glass called NH, and one boron-free aluminosilicate glass, TY. The aluminoborosilicate glass compositions are in the system $\mathrm{SiO}_{2}-\mathrm{Al}_{2} \mathrm{O}_{3}-\mathrm{B}_{2} \mathrm{O}_{3}-\mathrm{CaO}-\mathrm{Na}_{2} \mathrm{O}$; the ISG composition contains additional $\mathrm{ZrO}_{2}(\sim 1.7 \mathrm{~mol} . \%)$. The TY aluminosilicate glass composition is in the system $\mathrm{SiO}_{2}-\mathrm{Al}_{2} \mathrm{O}_{3}-\mathrm{CaO}-\mathrm{Na}_{2} \mathrm{O}$. Except for ISG (issued from an industrial batch), the $\mathrm{NH}$ and $\mathrm{TY}$ compositions were prepared from a mixture of oxides $\left(\mathrm{SiO}_{2}\right.$, $\left.\mathrm{B}_{2} \mathrm{O}_{3}, \mathrm{Al}_{2} \mathrm{O}_{3}, \mathrm{CaO}\right)$ and sodium carbonate $\left(\mathrm{Na}_{2} \mathrm{CO}_{3}\right)$. The powder mixtures were carefully ground into an agate mortar and were melted twice in a Pt crucible at $1150^{\circ} \mathrm{C}$ for $1 \mathrm{~h}$ for $\mathrm{NH}$ and at $1500^{\circ} \mathrm{C}$ for $20 \mathrm{~h}$ for TY (see [15] for details). Because the compositions studied by Jolivet et al. [15] are both $\mathrm{Na}$ - and Ca-bearing glasses, discriminating the I local environment between either $\mathrm{Ca}$ or $\mathrm{Na}$ is rendered difficult. Whereas the local charge compensation for I' by $\mathrm{Na}^{+}$cation is currently well admitted, the potential role for $\mathrm{Ca}^{2+}$ is currently not recognized. Therefore, we also investigated one glass composition C35 that is a Na-free Ca-rich glass. This investigated glass has the following composition: $31.8 \mathrm{SiO}_{2}, 29.2 \mathrm{~B}_{2} \mathrm{O}_{3}, 4.9 \mathrm{Al}_{2} \mathrm{O}_{3}, 32.5$ mol.\% $\mathrm{CaO}$; as provided by the analyses from Scanning Electron Microscopy coupled with Energy Dispersive X-ray Spectroscopy (SEM EDS).

We conducted the high-pressure experiments in a piston cylinder apparatus at temperatures between 1300 and $1500^{\circ} \mathrm{C}$ and for pressures between 0.5 and $1.5 \mathrm{GPa}$ using the pressurizing protocol described in Jolivet et al. [15]. The volatile-free glass powder were mixed with a known amount of solid $\mathrm{I}_{2}$. The mixture was loaded in a Pt capsule that was then sealed by arcwelding. The run duration was $\sim 4 \mathrm{~h}$ and the sample was quenched to room temperature by cutting off the power. The recovered samples consisted in clear glass covered with a dark residue suggesting an I excess during the experiments. The I excess was removed by cleaning 
in ethanol the glass samples. All the synthesised glasses was characterized by SEM EDS and the I content ranges from 0.5 to $2.5 \mathrm{~mol} . \%$ as reported in Jolivet et al. [15]. The I content measured in C35 is 1.6 mol.\%. The details of the sample composition are reported in Jolivet et al. [15] and are given in Supplementary Material and the I content measured for each glass is given in Table 1.

\subsection{X-ray Photoelectron Spectroscopy}

X-ray Photoelectron Spectroscopy was performed for several samples (see Table 1) to determine the I speciation in our glasses with the aim to provide constraints for the EXAFS simulations. Several crystalline standards $\left(\mathrm{NaI}, \mathrm{NaIO}_{3}\right.$ and $\left.\mathrm{CaI}_{2} \mathrm{O}_{6}\right)$ were also analysed, serving as a fingerprint for I speciation in the glasses. We could not acquire XPS spectra for solid crystalline $\mathrm{I}_{2}$ and $\mathrm{CaI}_{2}$ owing to the sublimation of $\mathrm{I}_{2}$ under high vacuum conditions and the poor stability of $\mathrm{CaI}_{2}$.

We carried out the XPS analyses with two spectrometers: a Kratos Nova and a Kratos Axis Ultra using a monochromatic $\mathrm{Al} \mathrm{K} \alpha$ radiation operating at $1486.6 \mathrm{eV}(15 \mathrm{kV}, 20 \mathrm{~mA})$ with a charge neutralizer. The glass chips $\left(\sim 3 \times 3 \mathrm{~mm}^{2}\right)$ showing a surface fracture from the bulk of the experimental charge were loaded into the sample chamber and at high vacuum $\left(<10^{-8}\right.$ mbar). The sample surface was not prepared and the analysis was conducted on a raw glass surface, hence avoiding possible surface contamination. The spot size on the sample is $300 \times 700 \mu \mathrm{m}^{2}$ area of analyses. We recorded survey spectra at a pass energy of $160 \mathrm{eV}$ corresponding to an overall instrument resolution measured on silver Fermi edge of $1.95 \mathrm{eV}$ and a step of $0.5 \mathrm{eV}$ from -5 to $1200 \mathrm{eV}$. High resolution spectra of $\mathrm{Na} 1 \mathrm{~s}, \mathrm{I} 3 \mathrm{~d}, \mathrm{O} 1 \mathrm{~s}, \mathrm{Ca} 2 \mathrm{p}$, C 1s core levels were recorded with an instrument resolution measured on silver Fermi of $0.49 \mathrm{eV}$ and a step of $0.1 \mathrm{eV}$ at a pass energy of $20 \mathrm{eV}$. The calibrations were performed on the adventitious $\mathrm{C} 1 \mathrm{~s}$ in the binding energy at $284.8 \mathrm{eV}[36,37]$. All spectra were treated with 
CasaXPS@ software. All spectra were fitted with a U2 Tougaard function [38] for the background and with a pseudo-Voigt function with a Lorentzian ratio of $50 \%$ for the various peaks. Although, the associated error on the different components provided by the CasaXPS@ fitting package is relatively low owing to the good quality of the XPS spectra, we believe that the simulations are accurate to within $10 \%$ of the derived value. Only the $\mathrm{I}_{3} 3 \mathrm{~d}_{5 / 2}$ peak in the I $3 \mathrm{~d}$ region with the highest intensity was fitted as compared to the one for the I $3 d_{3 / 2}$. The obtained peak position did not show dependency on I content or glass composition. Therefore, determining the exact nature of the charge-compensating cation (i.e. $\mathrm{Na}^{+}$or $\mathrm{Ca}^{2+}$ ) surroundings I atoms could not be possible. We obtained several acquisitions for each element. We did not find any modification of each individual acquisition suggesting that the glass is stable under the X-ray beam.

\subsection{X-ray Absorption Spectroscopy}

We collected the $\mathrm{I}_{3}$-edge XAS spectra on LUCIA beamline at SOLEIL synchrotron operating with a current of $450 / 500 \mathrm{~mA}$ and an energy of $2.75 \mathrm{GeV}$ [39]. The energy of the incoming photons was selected by using double crystal monochromator $\mathrm{Si}(111)$. The XAS spectra on the glass were collected in fluorescence mode with a silicon drift diode detector. To avoid the self-absorption effect, the geometry of the beamline was set to a low angle between the sample surface and the detector $\left(2^{\circ}\right)$. The energy calibration of the incoming photons was achieved on titanium foil by selecting the first inflexion point of the spectrum at $4966 \mathrm{eV}$. We used in our experiment an unfocused beam with a size of $4 \times 2 \mathrm{~mm}^{2}$ for maximizing the count rate. The glass powder samples were stuck on a copper plate using carbon tape and acquisition were conducted under vacuum conditions. Prior to acquisition, the region of interest for the X-ray fluorescence lines had to be optimised to avoid interferences arising from the proximity between Ca K-edge fluorescence line $(\sim 3691 \mathrm{eV})$ and the $\mathrm{I} \mathrm{L}_{3^{-}}$ edge fluorescence line $(\sim 3926 \mathrm{eV})$. The optimisation of the fluorescence region was 
conducted such as that the higher tail of the Ca fluorescence line did not contribute to the I signal. However, we suspect that removing the contribution of the Ca fluorescence line appears to be incomplete, especially for $\mathrm{C} 35$ in which $\mathrm{Ca}$ is 20 times more concentrated than I.

The XAS spectra were collected at the $\mathrm{L}_{3}$-edge of I in the range $4510-4850 \mathrm{eV}$. For each point, the counting time was $10 \mathrm{~s}$. We collected at least three spectra on each sample in order to obtain an average spectrum with a good signal to noise ratio. The recorded scans are identical and the presented spectra correspond to an average of the different scans. A slight colouring of the glass powder is observed after XAS acquisition. Several acquisitions were also made on crystalline standards for comparison and fingerprinting of the XAS glass spectra: $\mathrm{NaI}, \mathrm{CaI}_{2}, \mathrm{I}_{2}, \mathrm{NaIO}_{3}, \mathrm{CaI}_{2} \mathrm{O}_{6}$. In these crystalline compounds, the I oxidation state varies from -1 in iodides to +5 in iodates. As a result, the XAS signal (XANES and EXAFS) can be used for constraining the I oxidation state in the borosilicate glasses. Because crystalline iodides $\left(\mathrm{NaI}\right.$ and $\left.\mathrm{CaI}_{2}\right)$ are highly sensitive to $\mathrm{H}_{2} \mathrm{O}$ adsorption, the crystalline sample powders were stored in a sealed glove box and quickly loaded into the vacuum chamber for XAS analysis. We did not observe any visible sign of phase transformation under X-ray beam; moreover, repetitive scans on the crystalline powders were almost identical.

Both XANES and EXAFS spectra were simulated to determine the I speciation in glasses and the first coordination sphere around I atoms. The XAS spectra were reduced by using the DEMETER package $[40,41]$. The normalisation and the merge of the XAS spectra as well as the background removal were carried out with the Athena software [40,41]. In addition, the self-absorption effect was checked using the Fluo software implemented in Athena [40,41]. The first coordination sphere to I atoms was obtained from the simulation of the EXAFS signal by using the single scattering signals determined with known crystalline structure. We used $\mathrm{k}^{2}$-weighted signal function in the $\mathrm{k}$-space and the simulation of the EXAFS region was 
done using the Artemis software [41]. A description of the EXAFS fitting protocol is provided later in the Discussion section.

We simulated the ISG, NH, TY and C35 XANES spectra following the method described by Schlegel et al. [25] using a linear combination of the crystalline compound spectra. Linear fitting combinations were performed in the range 4540-4590 eV with the implemented tool in Athena software. It should be emphasised that the choice of crystalline structure for EXAFS or XANES spectrum simulations is based on the results obtained by the XPS, which provides the I speciation in the investigated glasses.

\section{Results}

\subsection{Iodine speciation by XPS}

We determined the I oxidation state using the XPS technique. The XPS spectra for crystalline compounds and glasses are shown in Fig. 1 . We chose to represent only the $3 \mathrm{~d}_{5 / 2}$ from the I doublet peak for clarity and because it is the most intense peak compared to the $3 d_{3 / 2}$ [42-44]. For crystalline powders, there is an obvious distinction in the XPS spectra between the I oxidation states and therefore I local environment. For $\mathrm{NaI}$ in which I is present as -1 oxidation state, there is a peak located at $\sim 619 \mathrm{eV}$; for $\mathrm{NaIO}_{3}$ and $\mathrm{CaI}_{2} \mathrm{O}_{6}$ in which $\mathrm{I}$ is present as +5 oxidation state, there is a peak located at $\sim 624 \mathrm{eV}$. For I-bearing glasses studied here, we observe in all the cases a single prominent peak located at $\sim 619 \mathrm{eV}$ (ranging from 619.0 to 619.4 eV obtained from the simulated spectra) and the absence of a peak at $\sim 624 \mathrm{eV}$. The presence of the peak at $619 \mathrm{eV}$ suggests that $\mathrm{I}$ is dissolved in the glass mostly as $\mathrm{I}^{-}$species. A keener scrutiny reveals a peak at $624.4 \mathrm{eV}$ for NH23-2 implying a small proportion of $\mathrm{I}^{5+}$ species within the glass. For several samples, we also observe a slight asymmetry on the highenergy side of the $619 \mathrm{eV}$ peak. We interpret this asymmetry as the possible presence of $\mathrm{I}_{2}$ species [45]. This suggests the possible presence of I dissolved in glasses as $I_{2}$ species. 
Furthermore, most of the investigated samples were clear glass indicating the absence of $\mathrm{I}_{2}$ -

249 filled bubbles. Brownish bubbles were only identified in TY glass samples and were interpreted as bubbles filled with residual $\mathrm{I}_{2}$.

251

Subsequent simulation of the $I 3 d_{5 / 2}$ peak reveals that $I_{2}$ is present as a dissolved species in glass. In NH23-2 glass, we have identified the presence of $\mathrm{I}^{5+}$ at a total I fraction of $3.0 \%$. The results of the simulations are shown in Table 1 with the I speciation and the XPS spectrum simulations are provided in Supplementary Material 1. In all investigated glasses, the quantitative simulation of the peak reveals that $\mathrm{I}$ is present on average as $95.6 \% \mathrm{I}^{-}$and $4.1 \%$ $\mathrm{I}_{0}$, presumably $\mathrm{I}_{2}$. The determination of the I speciation will be used for constraining the simulations conducted on both the $\mathrm{L}_{3}$-edge XANES and EXAFS.

Scrutinizing the I local environment with XPS simulations appears complicated, as the I $3 d_{5 / 2}$ peak position does not change as a function of glass composition. For instance, for C35 (i.e. $\mathrm{Na}$-free) for which the surrounding cation for $\mathrm{I}^{-}$is $\mathrm{Ca}^{2+}$ exhibits a peak maximum at $619.2 \mathrm{eV}$ comparable to the peak position observed for the other glasses that are $\mathrm{Na}$ - and $\mathrm{Ca}$-bearing compositions.

\subsection{L $_{3}$-edge XANES}

$\mathrm{L}_{3}$-edge XANES spectra for crystalline and I-bearing glasses are shown in Fig. 2. We provide the entire set of spectra in Supplementary Material 2. In Fig. 2, all spectra exhibit a main absorption edge located at $\sim 4563 \mathrm{eV}$. There is no pre-edge peak observed. The crystalline $\mathrm{I}_{2}$ spectrum is relatively featureless whereas the spectrum for other salts shows a distinguishable edge peak at $\sim 4563 \mathrm{eV}$, roughly symmetric except for $\mathrm{NaI}$ in which the edge peak seems to be a composition of several components. For iodates $\left(\mathrm{NaIO}_{3}\right.$ and $\left.\mathrm{CaI}_{2} \mathrm{O}_{6}\right)$, there is a strong shoulder with a maximum at $\sim 4574 \mathrm{eV}$. This peak is not clearly visible for NaI, however, we observe a peak at $\sim 4570 \mathrm{eV}$ and a broad feature extending up to $\sim 4590 \mathrm{eV}$ in the EXAFS 
region. For the iodates, there is a strong broad asymmetric peak with a maximum at $\sim 4592 \mathrm{eV}$ and corresponding to the beginning of the EXAFS region.

We followed the description provided by Schlegel et al. [25] for a tentative of assignment. The peaks at $\sim 4563$ and $\sim 4574 \mathrm{eV}$ are attributed to the transition to $5 \mathrm{~d}$ levels. The broad features observed are assigned to $2 \mathrm{p}$ to $\mathrm{d}$ transitions [14]. We did not attempt to determine the I oxidation state for crystalline compounds [46,47] as there is no apparent change in the edge position, and also because the line broadening is important at the L edge for heavy elements such as I. Instead, we use the crystalline spectra to decipher the I local environment in the studied glasses.

The I $L_{3}$-edge XANES spectra are reported for six glass samples. It should be emphasised that within a glass series (ISG, NH or TY) we did not observe any significant difference in between the spectra (see Supplementary Material 2) suggesting that I has comparable local environment for all samples of a given series. As observed in Fig. 2, the C35 XANES spectrum contrast to the spectra for $\mathrm{NH}$ and ISG, therefore indicating that the I local environment in C35 is not the same as the one in ISG and NH glasses. This observation appears in contrast to the XPS results showing that I is dissolved as $\mathrm{I}^{-}$, regardless of the glass composition. However, the XPS method only provides first level of information (i.e. I oxidation state) and does not scrutinize the next nearest neighbour to the I atoms.

The XANES spectra for ISG and NH look alike to the spectrum of NaI and to a lower extent to $\mathrm{CaI}_{2}$. This suggests that ISG and $\mathrm{NH}$ spectra are possibly a combination of both $\mathrm{NaI}$ and $\mathrm{CaI}_{2} \mathrm{XANES}$ spectra. There is a well-marked peak at $\sim 4563 \mathrm{eV}$ as well as a broad peak with a maximum at $\sim 4574 \mathrm{eV}$ and a broad shoulder at $\sim 4585 \mathrm{eV}$. Together, these features could witness the presence of $\mathrm{Ca}$ - and/or Na-iodates or a mixture between iodates and $\mathrm{Ca}$ - and/or Na-iodides; however, the XPS results obtained on those samples do not indicate the presence 
of $\mathrm{IO}_{3}{ }^{-}$molecular species in the glass structure. We did not observe the presence of unaccounted crystalline phase in the bulk of the glass as shown by the X-ray diagram obtained [15]. Therefore, the XANES signal recorded corresponds to the I local environment in the glass. The XANES spectrum for C35 that is Na-free glass composition has common features with the XANES spectrum for $\mathrm{CaI}_{2}$, however, as observed in Fig. 2, it appears unlikely that the C35 spectrum will be reproduced with only the spectrum from $\mathrm{CaI}_{2}$. This observation emphasises the difficulty to reproduce XANES spectrum for glasses with the sole use of XANES spectrum from crystalline compounds.

Nonetheless, in Fig. 3 we propose an attempt of XANES simulations using the method of linear combination described by schlegel et al. [25] to reproduce the XANES spectrum for the glasses. We strongly emphasise that this approach represents only an attempt and is by no mean an absolute result. The reason being that we simulate a XANES spectrum for a glass using XANES spectra obtained on crystalline compounds: $\mathrm{NaI}, \mathrm{CaI}_{2}, \mathrm{I}_{2}, \mathrm{NaIO}_{3}$ and $\mathrm{CaI}_{2} \mathrm{O}_{6}$, shown in Fig. 2. The simulation results are also provided in Table 1. The first step of the simulation involved using the entire set of spectra for crystalline compounds without constraints (except for C35 glass that is Na-free glass composition). We tested all the possible combinations to obtain the fit using the Linear Fitting Combination package. The entire set of simulation is provided in Supplementary Material 2. The combination results involving negative parameters were discarded. We limited the possible combination to three independent components. From Fig. 3, it can be observed that the simulated spectra do not reproduce entirely the measured I-bearing glass spectra. As mentioned, it appears difficult to completely reproduce the XANES glass spectra with the XANES crystalline spectra as it does not take into consideration the variations in bond length or bond angle that is a specificity of disordered glass materials (e.g. [48-52]). 
The XANES spectrum for TY33 is reproduced with a combination of $\mathrm{NaI}(\sim 66 \%), \mathrm{CaI}_{2}$ ( $14 \%)$, and a non-negligible proportion of $\mathrm{I}_{2}(\sim 21 \%)$. Considering that TY33 contains 0.5 mol. $\% \mathrm{I}$, the proportion of $\mathrm{I}_{2} \sim 0.1 \mathrm{~mol} . \%$. The presence of $\mathrm{I}_{2}$ appears consistent with the fact that TY glass samples showed a slight brownish colouring (see Jolivet et al. [15]). As shown in Table 1, the XANES simulation invoked the presence of iodate for several samples showing the highest I content. Except for NH23-2, this result does not appear consistent with the XPS results; however, at low concentration the presence of $\mathrm{NaIO}_{3}$ would not be detected by XPS measurements. For NH and ISG glasses, the XANES spectra are reproduced with a combination of $\mathrm{NaI}$ and $\mathrm{CaI}_{2}$ to more than $90 \%$ in proportion. The XANES simulations suggest the presence of $I_{2}$ in ISG and TY glasses. The ISG33-2 appears to be a particular case as the simulated amount of $\mathrm{I}_{2}$ is relatively high ( 40\%); although this is not consistent with the observed XPS results (see Table 1) suggesting that only $3.3 \%$ of I is dissolved as $\mathrm{I}_{2}$. A small contribution of iodate $\left(\mathrm{CaI}_{2} \mathrm{O}_{6}\right)$ is suggested in all $\mathrm{NH}$ glasses. If we consider $\mathrm{NH} 23-2$ with 2.5 mol.\% I dissolved, the proposed speciation will correspond to $\sim 2.2$ and $\sim 0.3$ mol.\% of iodide and iodate, respectively. For C35, the XANES spectrum is reproduced with a contribution of 92.9 and $7.1 \%$ from $\mathrm{CaI}_{2}$ and $\mathrm{CaI}_{2} \mathrm{O}_{6}$, respectively. This result is consistent to a certain extent to the XPS result that suggests I to be dissolved as I' species, although, the presence of $\mathrm{I}^{5+}$ has not been identified.

From the general point of view the results illustrated in Fig. 3 are consistent with the XPS results given in Table 1. The most important discrepancy is observed for ISG33-2 with 40\% $\mathrm{I}_{2}$ observed by XANES against $3 \%$ by XPS. In detail, it appears complicated to extract reliable I species proportions from the simulation of the XANES spectrum owing to the difficulty in simulating adequately the $\mathrm{I}_{3}$ XANES spectra for a glass with crystalline compounds; therefore there is a large error associated to the derived proportion from XANES simulation. 
Although the associated error to the simulation is probably large and the spectra are not reproduced adequately, it tends to discriminate the different iodide species present in the glass. Invariably, the best linear combination induces the presence of $\mathrm{NaI}$ and $\mathrm{CaI}_{2}$ suggesting that both iodide species are present in the glasses. This aspect is also strengthened by the fact that I can dissolve in the structure of the Na-free Ca-rich C35 glass composition. For instance, we failed to simulate the spectra with one and not the other iodide crystalline spectrum.

Nonetheless, in the current work and the subsequent XANES simulations, we propose that both $\mathrm{Na}^{+}$and $\mathrm{Ca}^{2+}$ are involved into the charge compensation of the $\mathrm{I}^{-}$species.

\subsection{L $L_{3}$-edge EXAFS}

$\mathrm{I}_{3}$-edge EXAFS spectra are shown in Fig. 4 for several glasses. We classified the spectra as a function of the I content and glass composition: from TY33 with 0.5 mol.\% I to NH23-2 with 2.5 mol.\% I. The spectrum for C35 is also added as this sample highlights the role of $\mathrm{Ca}^{2+}$ cations in the surrounding of $\mathrm{I}^{-}$species. Fig. 4 A represents the $\mathrm{k}^{2}$-weighted data. Fig. $4 B$ represents the amplitude of the radial distribution function (RDF) as obtained from the Fourier transforms of the oscillatory $\mathrm{k}^{2}$-weighted EXAFS signal in the $\mathrm{k}$-space. As a compromise between short and long distance, we chose to use the $\mathrm{k}^{2}$ oscillatory signal of the $\chi(\mathrm{k})$ function. In the k-space, the signal to noise ratio $(\mathrm{S} / \mathrm{N})$ of the oscillatory signal is changing between each sample. It appears that there is an increase in the $\mathrm{S} / \mathrm{N}$ with increasing I content. For instance, the NH23-2 with 2.5 mol.\% I has a good S/N whereas TY33 with 0.5 mol.\% the S/N is relatively poor. Owing to the data quality and in order to keep for each sample analysis the same range in the k-space spectra, the region used for the Fourier Transform of the EXAFS spectra is set between 2.5 and $6.7 \AA^{-1}$. This limit at $6.7 \AA^{-1}$ corresponds to the higher point usable for the data with the poor quality. 
In Fig.4B, the amplitude signal shows an intense peak with a maximum around $2.5 \AA$. This peak corresponds to the I first neighbour atoms. Surprisingly, the peak maximum is at higher position for C35: $2.82 \AA$, suggesting a longer distance to first neighbour. In addition, for C35 we observe a prominent peak located close to $1.5 \AA$ that we explain by the possible existence of $\mathrm{I}^{5+}$. This $\mathrm{I}^{5+}$ could be due to an evolution of the sample under the high energy of the X-ray beam during XAS acquisition. It appears consistent with the suggested result of the XANES fit but not with the XPS result that has a lower energy flux. In order to minimize the possible artefacts in the signal for this peak in the fitting procedure, we applied a background filter in the R space between 0 and $1.5 \AA$. The RDF peaks below $2.5 \AA$ do not correspond to any contribution from backscattering shells. In our case, the perturbations from the Ca excitation in the glass $\left(\sim 500 \mathrm{eV}\right.$ below the $\mathrm{I}_{3}$-edge $)$ can be considered weak compare to the noise due to the amorphous structure of the glass that decreases the EXAFS signal quickly after the threshold. The peak for TY33 is very weak and strongly overlapped with satellite scattering signal. As inferred earlier, the low $\mathrm{S} / \mathrm{N}$ in the $\mathrm{k}$-space will affect the definition of the I nearest neighbour in the R-space. Regardless of the glass chemical composition and I content, it appears that the peak maximum, which does not correspond to the actual distance between I atoms and its surrounding, are roughly identical to within $<0.1 \AA$ in radial distance. For instance, in borosilicate glasses NH23-1 (1.9 mol.\% I) has a peak maximum at $2.42 \AA$ whereas the ISG22-2 (1.2 mol.\% I) has a peak maximum at $2.40 \AA$. The boron-free TY33 has a peak maximum at $2.45 \AA$ comparable to the one observed for borosilicate glasses $\mathrm{NH}$ and ISG.

Hence, the distance between I and its surrounding for ISG, NH and TY would change between 2.8 and $3.0 \AA$; and is possibly higher for C35. The estimated distance for ISG, NH and TY is lower than the distance observed in iodide crystalline compounds: $\mathrm{r}_{\mathrm{Na}-\mathrm{I}}=3.24 \AA$ [51] and $\mathrm{r}_{\mathrm{Ca}-\mathrm{I}}=3.12 \AA$ [54]; however consistent with the distance reported in McKeown et al. 
393 [11] of $3.04 \AA$ in Na-bearing borosilicate glasses synthesised at ambient pressure. This

394 distance was attributed to I atoms surrounded by several $\mathrm{Na}$ atoms $[10,11]$. The estimated

395 distance to the nearest neighbour also seems consistent with the XANES simulation results

396 (Fig. 3) suggesting $\mathrm{Ca}$ and $\mathrm{Na}$ as the nearest neighbour to iodide species.

397 The objective in the treatment of the EXAFS spectra is to obtain an estimate on the

398 parameters for the first coordination sphere around I atoms: the average distance and the 399 coordination number to I atoms to the nearest neighbour. It should be emphasised that the

400

401

402

403

404

405

406

407

408

409

410 reported spectrum simulations and associated results represent only one possible solution. The I EXAFS simulations were conducted in the radial distance range between $\sim 1.5$ and $\sim 3.5 \AA$ (see Fig. 5). We could not investigate the signal to longer distance for several reasons: 1) the EXAFS S/N ratio did not allow it as shown in Fig. $4 \mathrm{~A}$ and 2) the proximity of the $\mathrm{L}_{2}$-edge line $(\sim 4850 \mathrm{eV})$ prevents from acquiring a long EXAFS signal. In order to obtain further information about I second or third neighbours, we would require a longer k-space acquisition than actually acquired. Due to the extremely low signal, we did not attempt to simulate the EXAFS spectra for TY glass samples but only on ISG, NH and C35 glass spectra. To conduct the simulations, we used standard crystalline structures taken from Crystallographic Open Database ([55] and references therein): $\mathrm{NaI}$ and $\mathrm{CaI}_{2}$. These structures were chosen in agreement with the XPS results and XANES simulations that suggest the presence of mostly iodide species dissolved in the glass structure. The presence of $\mathrm{I}_{2}$ and $\mathrm{CaI}_{2} \mathrm{O}_{6}$ was not considered in the simulation owing to the low abundances observed by XPS (see Table 1). For the particular case of $\mathrm{C} 35$, we only used the scattering path from $\mathrm{CaI}_{2}$ considering that the glass composition is Na-free.

Prior to the simulation, the EXAFS spectra were calibrated for the scattering amplitude and corrected for the edge position [56]. We simulated the spectrum obtained on $\mathrm{CaI}_{2}$ with the $\mathrm{CaI}_{2}$ crystalline model. We obtained $\mathrm{S}_{0}^{2}=0.984$ and $\Delta \mathrm{E}_{0}=-7.73 \mathrm{eV}$. We took the single 
scattering paths of each structure as given by the FEFF calculations in Artemis. For NaI, the path $\mathrm{Na}$ to I has Coordination Number $\left(\mathrm{CN}_{\mathrm{Na}-\mathrm{I}}\right)=6, \mathrm{r}_{\mathrm{Na}-\mathrm{I}}=3.236 \AA$; for $\mathrm{CaI}_{2}, \mathrm{CN}_{\mathrm{Ca}-\mathrm{I}}=3, \mathrm{r}_{\mathrm{Ca}-\mathrm{I}}$ $=3.117 \AA$. As McKeown et al. [11] derived an average $\mathrm{CN}_{\mathrm{Na}-\mathrm{I}}$ in their studied glasses close to 4, we choose a $\mathrm{CN}_{\mathrm{Na}-\mathrm{I}}=4$ and $\mathrm{CN}_{\mathrm{Ca}-\mathrm{I}}=2$ as starting guess prior to the simulations. The simulations are conducted in several steps: 1 ) the optimization of the distance to the first neighbour $\left(\mathrm{r}_{\mathrm{X}-\mathrm{I}}\right)$ is conducted with fixed initial coordination numbers $\left(\mathrm{CN}_{\mathrm{X}-\mathrm{I}}\right)$ and DebyeWaller attenuation factor $\left(\sigma^{2}\right) ; 2$ ) the optimization of the $\sigma^{2}$ is conducted at fixed $\mathrm{CN}_{\mathrm{X}-\mathrm{I}}$ and $\mathrm{r}_{\mathrm{X} \text { - }}$ I; 3) the optimization of the $\mathrm{CN}_{\mathrm{X}-\mathrm{I}}$ is conducted at fixed $\sigma^{2}$ and $\mathrm{r}_{\mathrm{X}-\mathrm{I}}$. Each category of parameter $\left(\mathrm{r}, \sigma^{2}\right.$ or $\left.\mathrm{CN}\right)$ is optimized for the whole set of scattering paths in the same time. We repeated the procedure several times until obtaining the best possible fit of the radial distance signal. We did not place any restraints on the parameter values to solve the EXAFS equation.

\section{Discussion}

\subsection{Local environment of iodine in aluminoborosilicate glasses}

EXAFS simulations are shown in Fig. 5 for NH23-2, ISG22-2 and C35. We present for each sample the fit of the RDF total amplitude (Fig. 5A) and the imaginary part (Fig. 5B). The fitting results $\left(\mathrm{CN}_{\mathrm{X}-\mathrm{I}}, \mathrm{r}_{\mathrm{X}-\mathrm{I}}\right.$ and $\left.\sigma_{\mathrm{X}-\mathrm{I}}^{2}\right)$ are given in Table 1 and Supplementary Material 2.

The results obtained on the nearest neighbour distance to I are comparable to the previous results from McKeown et al. [11]. For the iodide species (Ca-I and Na-I) and in the case of $\mathrm{Na}$ and Ca-bearing glasses (NH, ISG and TY), we obtain distances changing from 2.76 to $3.01 \AA$. On average the distance between $\mathrm{I}^{-}$and $\mathrm{Ca}^{2+}$ is shorter than the distance to $\mathrm{Na}^{+}$, which can be explained by the higher cationic charge of calcium for an equivalent ionic radius (1.20 and $1.24 \AA$ for $\mathrm{Na}^{+}$and $\mathrm{Ca}^{2+}$, respectively; [57]). We observe that the derived $\mathrm{r}_{\mathrm{X}-\mathrm{I}}$ are systematically lower than the one reported in McKeown et al. [11] (i.e. $3.04 \AA$ ). One reason for these lower I to first neighbour distances could be due to the intensive conditions (i.e. high- 
pressure) at which our glasses were held considering that high-pressure conditions are known to influence the local environment of cations [31-33]. On the other hand, as suggested, the derived $\mathrm{r}_{\mathrm{Ca}-\mathrm{I}}$ in the case of $\mathrm{C} 35$ is larger (3.60 $\mathrm{A}$ ) than the one derived for ISG and NH glasses. This aspect is currently unexplained; however, it should be pointed out that the C35 glass composition is significantly different from the ISG and NH glass compositions. It has more $\mathrm{B}_{2} \mathrm{O}_{3}(\sim 30 \mathrm{~mol} . \%)$ and less $\mathrm{SiO}_{2}(\sim 30 \mathrm{~mol} . \%)$ as compared to ISG and NH that could therefore greatly influence the glass structure. Furthermore, it is currently well-accepted that the distribution of network modifying cations within the glass structure is strongly affected by the nature of those cations in the so-called mixed alkali or alkaline-earth effect [58-61]. In the case of $\mathrm{Na}$ and $\mathrm{Ca}$-mixed silicate glass compositions (for instance similar to ISG, NH and TY), it has been shown that there is a strong intermixing between $\mathrm{Ca}^{2+}$ and $\mathrm{Na}^{+}$cations; in other words the oxygen negative charge compensation is preferably accomplished by both cations rather than only one sort of cation. As such, C35 represents a very peculiar glass composition that cannot be readily compared to ISG and NH ones. Nevertheless, it has the advantage to show that it is possible to find local environment of $\mathrm{I}^{-}$species surrounded by $\mathrm{Ca}^{2+}$ as a charge compensation cation.

We have reported the change in the derived $r_{X-I}$ as a function of I content in Fig. 6A. The point representative of $\mathrm{C} 35$ glass is not reported considering that this glass composition is not similar to the NH and ISG ones. From Fig. 6A, we do not observe a clear pattern as a function of I content, however, it seems that the highest $r_{X-I}$ are observed for the highest I content. For instance, in ISG glasses there is a slight increase in both Ca-I and Na-I bond lengths. We also observe that the $\mathrm{r}_{\mathrm{X}-\mathrm{I}}$ bond distances are systematically higher for $\mathrm{NH}$ glass than for ISG glass. It suggests that the I local environment is probably a function of the glass bulk composition.

465 Typically, the difference observed in $\mathrm{r}_{\mathrm{Ca}-\mathrm{I}}(>0.1 \AA)$ might be explained by the change in Ca content: 5.7 and $8.0 \mathrm{~mol} . \% \mathrm{CaO}$ in ISG and $\mathrm{NH}$, respectively. This would also be consistent 
with the higher $\mathrm{r}_{\mathrm{Ca}-\mathrm{I}}(3.60 \AA$, see Table 1) observed for $\mathrm{C} 35$ having $32.5 \mathrm{~mol} . \% \mathrm{CaO}$.

Although, $\mathrm{r}_{\mathrm{Na}-\mathrm{I}}$ seems less affected $(<0.1 \AA)$ for a larger variation in $\mathrm{Na}_{2} \mathrm{O}$ content: 12.6 and $24.2 \mathrm{~mol} \% \mathrm{Na}_{2} \mathrm{O}$ in ISG and $\mathrm{NH}$, respectively. Considering the small number of investigated compositions and samples, further work is currently requested to investigate the possible change of $r_{X-I}$ as a function of both I content and glass bulk composition.

In a similar manner, we have plotted the change in the $\mathrm{CN}_{\mathrm{X}-\mathrm{I}}$ values derived for iodide as a function of I content in Fig. $6 \mathrm{~B}$. The normalised $\mathrm{CN}_{\mathrm{X} \text {-I }}$ derived from the fit of the EXAFS signal provided in Table 1. For $\mathrm{Ca}$, the $\mathrm{CN}$ changes from 1.5 to 2.2. For $\mathrm{Na}$, the $\mathrm{CN}$ changes from 2.3 to 4.2 . The derived $\mathrm{CN}_{\mathrm{Na}-\mathrm{I}}$ of $2.3 \pm 0.2$ is anomalously low and is obtained for ISG31 glass sample having a low I content $(0.8 \mathrm{~mol} . \%)$ and synthesised at the lowest pressure $(0.5$ GPa). As shown in Fig. 6B, we do not observe any correlation between the derived $\mathrm{CN}$ and the I content. The $\mathrm{CN}_{\mathrm{Ca}-\mathrm{I}}$ exhibits the lowest variation in coordination number. The average $\mathrm{CN}_{\mathrm{Na}}$ I and $\mathrm{CN}_{\mathrm{Ca}-\mathrm{I}}$ (not including the $\mathrm{C} 35$ value of 1.5 ) are $3.6 \pm 0.6$ and $2.0 \pm 0.1$, respectively. The higher $\mathrm{CN}_{\mathrm{Na}-\mathrm{I}}$ is consistent with the lower positive charges of $\mathrm{Na}$ as compared to $\mathrm{Ca}$ to compensate the negative charges of the iodide.

The obtained CN values cover the lower end range reported in McKeown et al. [11] (Fig. 7). We plotted the obtained normalised $\mathrm{CN}_{\mathrm{X} \text {-I }}$ values as a function of the obtained $\mathrm{r}_{\mathrm{X} \text {-I }}$ values for iodide species in Fig. 7. We also reported the experimental data points from McKeown et al. [11] for comparison. We observe that our I-bearing glasses synthesised under high-pressure conditions have comparable $\mathrm{r}_{\mathrm{X}-\mathrm{I}}$ bond length as the one reported in McKeown et al. [11]. The derived $\mathrm{CN}_{\mathrm{X}-\mathrm{I}}$ have a narrower range as compared to the values reported in McKeown et al. [11]. The possible reasons for lower $\mathrm{CN}_{\mathrm{X}-\mathrm{I}}$ values could be: 1) the intensive pressure conditions are responsible for the lower derived $\mathrm{CN}_{\mathrm{X}-\mathrm{I}} ; 2$ ) the higher dissolved I content induces a lower global charge compensation in the surrounding of $\mathrm{I}^{-}$species. 
We applied bond valence theory using the bond valence parameters reported in Brese and O'Keeffe [62]. We used the following equation that relates the I valence $\left(v_{\mathrm{X}-\mathrm{I}}\right)$ to the bond length $\left(\mathrm{d}_{\mathrm{X}-\mathrm{I}}\right)$ :

$v_{X-I}=\exp \left(\frac{R_{X-I}-d_{X-I}}{b}\right)$ Eq. 2

Where $\mathrm{X}$ is the cation (i.e. $\mathrm{Na}^{+}$or $\mathrm{Ca}^{2+}$ ), $\mathrm{r}_{\mathrm{X} \text {-I }}$ is the bond valence parameter: 2.56 and 2.72 for $\mathrm{Na}^{+}$and $\mathrm{Ca}^{2+}$, respectively; $\mathrm{b}$ is a constant 0.37 . The valence $v_{\mathrm{X}-\mathrm{I}}$ is related to the $\mathrm{CN}$ with the following relation $v=\mathrm{z} / \mathrm{CN}$, where $\mathrm{z}$ is the cation charge. Using the average $\mathrm{CN}$ derived from EXAFS simulation (i.e. 3.6 and 2.0 for $\mathrm{Na}$ and $\mathrm{Ca}$ ); we obtain $\mathrm{d}_{\mathrm{X}-\mathrm{I}}$ of 3.03 and $2.72 \AA$ for Na-I and Ca-I bond length, respectively. These values are in good agreement with the obtained values in Table 1 from EXAFS. The calculated $\mathrm{d}_{\mathrm{X}-\mathrm{I}}$ value for Ca-I bond appear lower than the one derived from EXAFS $(2.85 \pm 0.09 \AA$ on average for Ca-I). Bond valence theory calculates a bond length without considering possible surrounding perturbation, however, $\mathrm{Na}^{+}$and $\mathrm{Ca}^{2+}$ cations do not only share their positive charges to $\mathrm{I}^{-}$anions but also to oxygen atoms from the silicate and borate networks within the glass [63]. Thus, due to the perturbation brought by surrounding oxygen atoms, the measured distance to I by EXAFS is expected to be different from the one calculated with the bond valence theory.

\subsection{Iodine dissolution mechanism during a high-pressure experiment under oxidizing} conditions

In the present work, we have shown that $\mathrm{I}$ is mostly dissolved as iodide species $\left(\mathrm{I}^{-}\right)$. This behaviour was expected and is consistent with previous studies on the I dissolution mechanisms in borosilicate glasses [9-11,13] and the chemical reaction for I dissolution represented by Eq. 1 in which an $\mathrm{I}_{2}$ molecule from the fluid phase interacts with $\mathrm{Na}$ atoms in the melt phase to form both $\mathrm{NaI}$ and $\mathrm{NaIO}_{3}$ in the melt. Based on the XANES and EXAFS 
results, we propose an additional reaction involving the $\mathrm{Ca}$ as a possible nearest neighbour for I' such as:

$6 I_{2}^{f l}+6 \mathrm{CaO}^{m} \rightarrow 5 \mathrm{CaI}_{2}^{m}+\mathrm{CaI}_{2} \mathrm{O}_{6}^{m} \quad$ Eq. 3

However, these two chemical reactions suffer from the fact that iodates are not observed in our glasses or at extremely low concentrations; lower than the 1/5 ratio in Eq. 1 and 3. In the absence of $\mathrm{I}^{5+}$ dissolved as iodate or the absence of cation capable of changing its oxidation state (e.g. Fe changing from $\mathrm{Fe}^{2+}$ to $\left.\mathrm{Fe}^{3+},[10]\right)$, there is an excess of negative charges due to the reduction of $\mathrm{I}_{2}{ }^{\mathrm{fl}}$ into $\mathrm{I}^{-}$. One possible solution is to invoke an exchange between I and oxygen from the melt with oxygen released in the fluid phase during the experiments such as:
$I_{2}^{f l}+O^{2-, m} \rightarrow 2 I^{-, m}+O_{2}^{f l}$
Eq. 4

Unfortunately, we have no way to test this hypothesis, besides we were not able to measure the $\mathrm{O}_{2}{ }^{\mathrm{fl}}$ concentration at the capsule opening after the experiments. The nature of oxygen that can be involved in this reaction is still to be determined [19,64-67]. At first level of knowledge, the obvious candidate is to use Non-Bridging Oxygen (NBO) in the melt structure, however, it could be NBOs from the silicate network or from the borate network $[19,65]$. Jolivet et al. [15] suggested that the I dissolution is accompanied by a change in the distribution of boron species (i.e. $\mathrm{BO}_{3}$ and $\mathrm{BO}_{4}$ ). Based on the Raman spectroscopic results, they also showed that the silicate network appears unaffected by the I dissolution. In that case, we expect an interplay between I atoms and the borate network with an increase in the $\mathrm{BO}_{3}$ species and decrease in $\mathrm{BO}_{4}$. If it is currently observed for ISG glass samples, it is the opposite of $\mathrm{NH}$ glass samples: $\mathrm{BO}_{4}$ increases with increasing I content and $\mathrm{BO}_{3}$ decreases. In any case, further experimental work is currently required using ${ }^{17} \mathrm{O}$ NMR to determine the nature of the oxygen involved in the dissolution mechanisms of iodine as I- species.

\section{Conclusion}


In the subsequent work, we have investigated the local environment of I atoms dissolved in glasses of various compositions synthesised under high-pressure conditions. To do so, we used two complementary spectroscopic methods: XPS and $\mathrm{I} \mathrm{L}_{3}$-edge XAS. The studied glasses are from three different compositions fully detailed in Jolivet et al. [15]. The range of I investigated is 0.5 to $2.5 \mathrm{~mol} . \%$.

With the XPS, we show unambiguously that I is mostly dissolved as iodide ( $\left.\mathrm{I}^{-}\right)$species. However, we could also observe small proportions of other species such $\mathrm{I}_{2}$ and $\mathrm{CaI}_{2} \mathrm{O}_{6}$. Such a speciation is also confirmed with the modelling of the $\mathrm{I}_{3}$-edge XANES using simple spectrum linear combination. In addition, it also infers that $\mathrm{Na}^{+}$is not the only nearest neighbour of I atoms and we propose that $\mathrm{Ca}^{2+}$ cations are also acting as a charge balancing cations to the negative charges on $\mathrm{I}^{-}$.

The simulation of the EXAFS spectra suggests that on average $\mathrm{I}^{-}$anions has a bond length of 2.98 to $2.85 \AA$ to the nearest neighbour, either $\mathrm{Na}^{+}$or $\mathrm{Ca}^{2+}$. This range of values is consistent with previous investigations. We derived a coordination number to $\mathrm{Na}$ of 3.6 and to $\mathrm{Ca}$ of 2.0.

The main outcome of those results is that $\mathrm{Ca}$ is able, like $\mathrm{Na}$, to dissolve $\mathrm{I}$ in its surrounding. This new observation is likely due to the high pressure conditions used for synthesising the $\mathrm{I}^{-}$ bearing borosilicate glasses. Although the question of I-bearing glass matrix is to be determined, we show that solubilizing I in glass matrix at high pressure is a promising protocol to immobilize radioactive ${ }^{129} \mathrm{I}$ in nuclear waste glasses.

\section{Acknowledgements}

The authors are grateful to the Région Pays de Loire that financed the current work through the Pari Scientifique "CIPress" project. The authors thank the University of Nantes and the CNRS for their access to analytical facilities. We acknowledge SOLEIL for provision of synchrotron radiation facilities and we would like to thank LUCIA staff for assistance in 
using the beamline. We wish to thank Prof. Nicolas Dacheux for handling our manuscript and the three anonymous reviewers who helped for greatly improving our manuscript.

\section{References}

[1] Michel, R., Daraoui, E., Gorny, M., Jakob, D., Sachse, R., Tosch, L., Nies, H., Goroncy, I., Herrmann, J., Synal, H.-A., Stocker, M., Alfimov, V., 2012. Iodine-129 and Iodine-127 in European seawaters and in precipitation from Northern Germany. Sci. Tot. Env. 419, 151169.

[2] Chen, X., Gong, M., Yi, P., Aldahan, A., Yu, Z., Possnert, G., Chen, L., 2015. Distribution of ${ }^{129}$ I in terrestrial surface water environments. Nuc. Inst. Meth. Phys. Res. B 361, 604-608. [3] Sinnott, B., Ron, E., Schneider, A.B., 2010. Exposing the thyroid to radiation: a review of its current extent, risks, and implications. Endocr. Rev. 31, 756-773.

[4] Campayo, L., Grandjean, A., Coulon, A., Delorme, R., Vantelon, D., Laurencin, D., 2011. Incorporation of iodates into hydroxyapatites: a new approach for the confinement of radioactive iodine. J. Mat. Chem. 21, 17609.

[5] Riley, B.J., Vienna, J.D., Strachan, D.M., McCloy, J.S., Jerden, J.L.Jr., 2016. Materials and processes for the effective capture and immobilization of radioiodine: A review. J. Nuc. Mat. 470, 307-326.

[6] Watanabe, Y., Ikoma, T., Yamada, H., Suetsugu, Y., Komatsu, Y., Stevens, G.W., Moriyoshi, Y., Tanaka, J., 2009. Novel long-term immobilization method for radioactive iodine-129 using a zeolite/apatite composite sintered body. App. Mat. Interfaces 1, 15791584.

[7] Maddrell, E., Gandy, A., Stennett, M., 2014. The durability of iodide sodalite. J. Nuc. Mat. $449,168-172$. 
585

586

587

588

589

590

591

592

593

594

595

596

597

598

599

600

601

602

603

604

605

[8] Coulon, A., Grandjean, A., Laurencin, D., Jollivet, P., Rossignol, S., Campayo, L., 2017.

Durability testing of an iodate-substituted hydroxyapatite designed for the conditioning of ${ }^{129}$ I. J. Nuc. Mat. 484, 324-331.

[9] Muller, I.S., McKeown, D.A., Pegg, I.L., 2014. Structural Behavior of Tc and I Ions in Nuclear Waste Glass. Proc. Mater. Sci. 7, 53-59.

[10] Riley, B.J., Schweiger, M.J., Kim, D.S., Lukens, W.W., Williams, B.D., Iovin, C.,

Rodriguez, C.P., Overman, N.R., Bowden, M.E., Dixon, D.R., et al., 2014. Iodine solubility in a low-activity waste borosilicate glass at $1000{ }^{\circ} \mathrm{C}$. J. Nuc. Mat. 452, 178-188.

[11] McKeown, D.A., Muller, I.S., Pegg, I.L., 2015. Iodine valence and local environments in borosilicate waste glasses using X-ray absorption spectroscopy. J. Nuc. Mater. 456, 182-191.

[12] Hmra, P., 2010. Retention of halogens in waste glass. U.S. department of energy.

[13] Cicconi, M.R., Pili, E., Grousset, L., Neuville, D.R., 2019a. The influence of glass composition on iodine solubility. Mat. Res. Soc. 4, 17-18.

[14] Cicconi, M.R., Pili, E., Grousset, L., Florian, P., Bouillard, J.C., Vantelon, D., Neuville, D.R., 2019b. Iodine solubility and speciation in glasses. Sci. Rep. 9, 7758.

[15] Jolivet, V., Morizet, Y., Paris, M., Suzuki-Muresan, T., 2020. High pressure experimental study on iodine solution mechanisms in nuclear waste glasses. J. Nuc. Mat. 533, 152112.

[16] Bureau, H., Auzende, A.L., Marocchi, M., Raepsaet, C., Munsch, P., Testemale, D., Mézouar, M., Kubsky, S., Carrière, M., Ricolleau, A., et al., 2016. Modern and past volcanic degassing of iodine. Geochim. Cosmochim. Acta 173, 114-125. 
[17] Leroy, C., Bureau, H., Sanloup, C., Raepsaet, C., Glazirin, K., Munsch, P., Harmand, M., Prouteau, G., Khodja, H., 2019. Xenon and iodine behaviour in magmas. Earth Planet. Science Lett. 522, 144-154.

[18] Dell, W.J., Bray, P.J., Xiao, S.Z., 1983. ${ }^{11}$ B NMR studies and structural modeling of $\mathrm{Na}_{2} \mathrm{O}-\mathrm{B}_{2} \mathrm{O}_{3}-\mathrm{SiO}_{2}$ glasses of high soda content. J. Non-Cryst. Solids 58, 1-16.

[19] Du, L.S., Stebbins, J.F., 2005. Network connectivity in aluminoborosilicate glasses: A high-resolution ${ }^{11} \mathrm{~B},{ }^{27} \mathrm{Al}$ and ${ }^{17} \mathrm{O}$ NMR study. J. Non-Cryst. Solids 351, 3508-3520.

[20] Jolivet, V., Jossé, L., Rivoal, M., Paris, M., Morizet, Y., La, C., Suzuki-Muresan, T., 2019. Quantification of boron in aluminoborosilicate glasses using Raman and ${ }^{11}$ B NMR. J. Non-Cryst. Solids 511, 50-61.

[21] Fuhrmann, M., Bajt, S., Schoonen, M.A.A., 1998. Sorption of iodine on minerals investigated by X-ray absorption near edge structure (XANES) and ${ }^{129}$ I tracer sorption experiments. App. Geochem. 13, 127-141.

[22] Laurencin, D., Vantelon, D., Briois, V., Gervais, C., Coulon, A., Grandjean, A., Campayo, L., 2014. Investigation of the local environment of iodate in hydroxyapatite by combination of X-ray absorption spectroscopy and DFT modelling. RSC Adv. 4, 1470014707.

[23] Podder, J., Lin, J., Sun, W., Botis, S.M., Tse, J., Chen, N., Hu, Y., Li, D., Seaman, J., Pan, Y., 2017. Iodate in calcite and vaterite: Insights from synchrotron X-ray absorption spectroscopy and first-principles calculations. Geochim. Cosmochim. Acta 198, 218-228.

[24] Feiters, M.C., Küpper, F.C., Meyer-Klaucke, W., 2004. X-ray absorption spectroscopic studies on model compounds for biological iodine and bromine. J. Synchr. Rad. 12, 85-93. 
[25] Schlegel, M.L., Reiller, P., Mercier-Bion, F., Barré, N., Moulin, V., 2006. Molecular environment of iodine in naturally iodinated humic substances: Insight from X-ray absorption spectroscopy. Geochim. Cosmochim. Acta 70, 5536-5551.

Inorg. Chem. 4147-4152.

[26] Yamaguchi, N., Nakano, M., Tanida, H., Fujiwara, H., Kihou, N., 2006. Redox reaction of iodine in paddy soil investigated by field observation and the I K-edge XANES fingerprinting method. J. Environ. Radioact. 86, 212-226.

[27] Reed, W.A., May, I., Livens, F.R, Charnock, J.M., Jeapes, A.P., Gresley, M., Mitchell, R.M., Knight, P., 2002. XANES fingerprinting of iodine species in solution and speciation of iodine in spent solvent from nuclear fuel reprocessing. J. Anal. At. Spectrom. 17, 541-543.

[28] Rocca, F., Dalba, G., Fornasini, P., Tomasi, A., 1992. Structural study of AgI-Ag $2 \mathrm{O}-$ $\mathrm{B}_{2} \mathrm{O}_{3}$ glasses by X-ray absorption spectroscopy. Solid State lonics 53-56, 1253-1259.

[29] Lee, C.W., Pyo, J.-Y., Park, H.-S., Yang, J.H., Heo, J., 2017 Immobilization and bonding scheme of radioactive iodine-129 in silver tellurite glass. J. Nuc. Mat. 492, 239-243.

[30] Chabauty, A.-L., Campayo, L., Méar, F.O., Montagne, L., 2019. Niobium- and bismuthsilver phosphate glasses for the conditioning of radioactive iodine. J. Non-Cryst. Solids 510, $51-61$.

[31] Allwardt, J.R., Stebbins, J.F., Terasaki, H., Du, L.-S., Frost, D.J., Withers, A.C., Hirschmann, M.M., Suzuki, A., Ohtani, E., 2007. Effect of structural transitions on properties of high-pressure silicate melts: ${ }^{27} \mathrm{Al}$ NMR, glass densities, and melt viscosities. Am. Mineral. 92, 1093-1104. 
[32] Lee, S.K., Kim, H.N., Lee, B.H., Kim, H.I., Kim, E.J., 2010. Nature of chemical and topological disorder in borogermanate glasses: Insights from B-11 and O-17 Solid-State NMR and quantum chemical calculations. J. Phys. Chem. B. 114, 412-420.

[33] Wilding, M., Guthrie, M., Kohara, S., Bull, C.L., Akola, J., Tucker, M.G., 2012. The structure of $\mathrm{MgO}-\mathrm{SiO}_{2}$ glasses at elevated pressure. J. Phys. Condens. Matter 24, $225403-$ 225414.

[34] Morizet, Y., Vuilleumier, R., Paris, M., 2015. A NMR and molecular dynamics study of $\mathrm{CO}_{2}$-bearing basaltic melts and glasses. Chem. Geol. 418, 89-103.

[35] Gin, S., Abdelouas, A., Criscenti, L.J., Ebert, W.L., Ferrand, K., Geisler, T., Harrison, M.T., Inagaki, Y., Mitsui, S., Mueller, K.T., et al., 2013. An international initiative on longterm behavior of high-level nuclear waste glass. Mater. Today 16, 243-248.

[36] Barr, T.L., Seal, S., 1995. Nature of the use of adventitious carbon as a binding energy standard. J. Vac. Sci. Tech. A 13, 1239-1246.

[37] Miller, D.J., Biesinger, M.C., McIntyre, N.S., 2002. Interactions of $\mathrm{CO}_{2}$ and $\mathrm{CO}$ at fractional atmosphere pressures with iron and iron oxide surfaces: one possible mechanism for surface contamination? Surf. Interface Anal. 33, 299-305.

[38] Tougaard, S., 1997. Universality classes of inelastic electron scattering cross- sections. Surf. Inter. Anal. 25, 137-154.

[39] Vantelon, D., Trcera, N., Roy, D., Moreno, T., Mailly, D., Guillet, S., Metchalkov, E., Delmotte, F., Lassalle, B., Lagarde, P., Flank, A.M., 2016. The LUCIA beamline at SOLEIL. J. Synchr. Rad. 23, 635-640.

[40] Newville, M., Ravel, B., Haskel, D., Rehr, J. J., Stern, E.A., Yacoby, Y., 1995. Analysis of multiple-scattering XAFS data using theoretical standards. Physica B 208/209, 154-156. 
672 [41] Ravel, B., Newville, M., 2005. ATHENA, ARTHEMIS, HEPHAESTUS: data analysis

673 for Xray absorption spectroscopy using IFEFFIT. J. Synchr. Rad. 12, 537-541.

674 [42] Tojo, T., Tachikawa, T., Fujitsuka, M., Majima, T., 2008. Iodine-doped $\mathrm{TiO}_{2}$

675 photocatalysts: Correlation between band structure and mechanism. J. Phys. Chem. C 112, $676 \quad 14948-14954$.

677 [43] Marinoiu, A., Gatto, I., Raceanu, M., Varlam, M., Moise, C., Pantazi, A., Jianu, C.,

678 Stefanescu, I., Enachescu, M., 2017. Low cost iodine doped graphene for fuel cell electrodes.

679 Int. J. Hydrogen Energy 42, 26877-26888.

680 [44] Xiang, P., Lv, F., Xiao, T., Jiang, L., Tan, X., Shu, T., 2018. Improved performance of 681 quasi-solid-state dye-sensitized solar cells based on iodine-doped $\mathrm{TiO}_{2}$ spheres photoanodes.

682 J. Alloys Compounds 741, 1142-1147.

[45] Moulder, J.F., Stickle, W.F., Sobol, P.E., Bomben, K.D., 1992. Handbook of W-ray

Photoelectron Spectroscopy: a reference book of standard spectra for identification and interpretation of XPS spectra. J. Chastain Ed., Perkin-Elmer Corporation Physical Electronics Division, Eden Prairie, Minnesota.

687 [46] Brown, G.E.Jr., Calas, G., Waychunas, G.A., Petiau, J., 1988. X-ray absorption spectroscopy and its applications in mineralogy and geochemistry. Rev. Mineral. 18, 431-512. molecular dynamics simulation. J. Non-Cryst. Solids 349, 66-79. 
693

694

695

696

697

698

699

700

701

702

703

704

705

706

707

708

709

710

711

712

713

714

715

[49] Benoit, M., Profeta, M., Mauri, F., Pickard, C.J., Tuckerman, M.E., 2005. First-principles calculation of the ${ }^{17} \mathrm{O}$ NMR parameters of a calcium aluminosilicate glass. J. Phys. Chem. B $109,6052-6060$.

[50] Farnan, I., Grandinetti, P.J., Baltisberger, J.H., Stebbins, J.F., Werner, U., Eastman, M.A., Pines, A., 1992. Quantification of the disorder in network-modified silicate glasses. Nature 358, 31-35.

[51] Liu, Y., Nekvasil, H., Tossell, J., 2005. Explaining the effects of T-O-T bond angles on NMR chemical shifts in aluminosilicates: A Natural Bonding Orbital (NBO) and Natural Chemical Shielding (NCS) analysis. J. Phys. Chem. A 109, 3060-3066.

[52] Massiot, D., Messinger, R.J., Cadars, S., Deschamps, M., Montouillout, V., Pellerin, N., Veron, E., Allix, M., Florian, P., Fayon, F., 2013. Topological, geometric, and chemical order in materials: insights from solid-state NMR. Acc. Chem. Res. 46, 1975-1984.

[53] Wyckoff, R.W.G., 1963. Rocksalt structure Crystal Structures, Second edition. Interscience Publishers, New York, New York, 1963, 1, 85-237.

[54] Blum, H, 1933. Die Kristallstruktur des wasserfreien Magnesiumjodids und Calciumjodids. Zeitschrift fuer Physikalische Chemie, Abteilung B: Chemie der Elementarprozesse, Aufbau der Materie 22, 298-304.

[55] Quirós, M., Gražulis, S., Girdzijauskaitè, S., Merkys, A., Vaitkus, A., 2018. Using SMILES strings for the description of chemical connectivity in the Crystallography Open Database. J. Cheminformatics 10, 23.

[56] Morizet, Y., Trcera, N., Larre, C., Rivoal, M., Le Menn, E., Vantelon, D., Gaillard, F., 2019. X-ray absorption spectroscopic investigation of the $\mathrm{Ca}$ and $\mathrm{Mg}$ environments in $\mathrm{CO}_{2}$ bearing silicate glasses. Chem. Geol. 510, 91-102. 
716 [57] Whittaker, E.J.W., Muntus, R., 1970. Ionic radii for use in geochemistry. Geochim.

717 Cosmochim. Acta 34, 945-956.

718 [58] Lee, S.K., Stebbins, J.F., 2003. Nature of cation mixing and ordering in Na-Ca silicate 719 glasses and melts. J. Phys. Chem. B 107, 3141-3148.

720

721

722

723

724

725

726

727

728

729

730

731

732

733

734

735

736

737

[59] Allwardt, J.R., Stebbins, J.F., 2004. Ca-Mg and K-Mg mixing around non-bridging O atoms in silicate glasses: An investigation using ${ }^{17} \mathrm{O}$ MAS and 3QMAS NMR. Am. Mineral. $89,777-784$.

[60] Kelsey, K.E., Allwardt, J.R., Stebbins, J.F., 2008. Ca-Mg mixing in aluminosillicate glasses: An investigation using ${ }^{17} \mathrm{O}$ MAS and $3 \mathrm{QMAS}$ and ${ }^{27} \mathrm{Al}$ MAS NMR. J. Non-Cryst. Solids 354, 4644-4653.

[61] Le Losq, C., Neuville, D.R., 2013. Effect of the $\mathrm{Na} / \mathrm{K}$ mixing on the structure and the rheology of tectosilicate silica-rich melts. Chem. Geol. 346, 57-71.

[62] Brese, N.E., O'Keeffe, M., 1991. Bond-valence parameters for solids. Acta Crystallogr. B 47, 192-197.

[63] Cormier, L., Cuello, G.J., 2013. Structural investigation of glasses along the $\mathrm{MgSiO}_{3}-$ $\mathrm{CaSiO}_{3}$ join: Diffraction studies. Geochim. Cosmochim. Acta 122, 498-510.

[64] Stebbins, J.F., Zhao, P., Kroeker, S., 2000. Non-bridging oxygens in borate glasses: characterization by ${ }^{11} \mathrm{~B}$ and ${ }^{17} \mathrm{O}$ MAS and 3QMAS NMR. Solid State Nuc. Magn. Res. 16, 919.

[65] Du, L.S., Allwardt, J.R., Schmidt, B.C., Stebbins, J.F., 2004. Pressure-induced structural changes in a borosilicate glass-forming liquid: Boron coordination, non-bridging oxygens, and network ordering. J. Non-Cryst. Solids 337, 196-200. 
738 [66] Lee, S.K., Sung, S., 2008. The effect of network-modifying cations on the structure and 739 disorder in peralkaline Ca-Na aluminosilicate glasses: O-17 3Q MAS NMR study. Chem. 740 Geol. 2008, 256, 326-333.

741 [67] Morizet, Y., Florian, P., Paris, M., Gaillard, F., 2017. ${ }^{17}$ O NMR evidence of free ionic 742 clusters $\mathrm{M}^{\mathrm{n}+} \mathrm{CO}_{3}{ }^{2-}$ in silicate glasses: Precursors for carbonate-silicate liquids immiscibility. $743 \quad$ Am. Mineral. 102, 1561-1564. 
746

747

Figure 1: XPS spectra in the I $3 \mathrm{~d}_{5 / 2}$ energy region obtained on I-bearing glasses of ISG and NH compositions from Jolivet et al. [15] along with XPS spectra for crystalline compounds: $\mathrm{NaI}, \mathrm{NaIO}_{3}$ and $\mathrm{CaI}_{2} \mathrm{O}_{6}$. The peak at $\sim 619 \mathrm{eV}$ is attributed to $\mathrm{I}^{-}$species and the peak at $\sim 624$ $\mathrm{eV}$ is attributed to $\mathrm{I}^{5+}$ species.

Figure 2: $\mathrm{I} \mathrm{L}_{3}$-edge XANES spectra for I-bearing glasses (ISG, NH, TY and C35) and solid crystalline compounds $\left(\mathrm{I}_{2}, \mathrm{NaI}, \mathrm{CaI}_{2}, \mathrm{NaIO}_{3}\right.$ and $\left.\mathrm{CaI}_{2} \mathrm{O}_{6}\right)$ in the $4540-4600 \mathrm{eV}$ region. The strong feature at $4563 \mathrm{eV}$ corresponds to the white line and is visible on almost all spectra except $\mathrm{I}_{2}$ that exhibits relatively featureless spectrum. There are two broad peaks located at $\sim 4574$ and $4590 \mathrm{eV}$ are assigned to transitions in the $5 \mathrm{~d}$ levels and $2 \mathrm{p}$ to $\mathrm{d}$, respectively.

Figure 3: Linear Combination Fitting of the $\mathrm{I} \mathrm{L}_{3}$-edge XANES spectra for I-bearing glasses (A, TY33; B, ISG22-2; C, NH23-2; and D, C35) with spectra from crystalline compounds. The residual from the fit is also shown. The derived proportion of each component is reported and is a combination of $\mathrm{NaI}, \mathrm{CaI}_{2}, \mathrm{I}_{2}$ and to a lower part $\mathrm{CaI}_{2} \mathrm{O}_{6}$ (see Table 1).

Figure 4: Typical $\mathrm{I}_{3}$-edge EXAFS spectra for investigated glasses and represented in the kspace (A) and R-space (B). Spectra are stacked with increasing I content from TY33 (0.5 mol.\%) to NH23-2 (2.5 mol.\%). In addition, spectrum from C35 (1.6 mol.\%) is also reported. The strong peak at $\sim 2.5 \AA$ corresponds to the actual EXAFS signal for the nearest neighbour of the I atoms.

Figure 5: Examples of $\mathrm{I} \mathrm{L}_{3}$-edge EXAFS simulation of the RDF for NH23-2 (A), ISG22-2 (B) and C35 (C). The simulation of the imaginary part of the EXAFS signal is also shown. The simulation are conducted in the 1.5 to $3.5 \AA$ A region to derive the $\mathrm{CN}_{\mathrm{X}-\mathrm{I}}$ and $\mathrm{r}_{\mathrm{X}-\mathrm{I}}$. We used single scattering paths from crystalline structure: $\mathrm{NaI}$ and $\mathrm{CaI}_{2}$, in agreement with the 
observed components from XANES simulations. The EXAFS fitting results are reported in Table 1.

770 Figure 6: Change in the derived $\mathrm{r}_{\mathrm{X}-\mathrm{I}}$ in $\AA$ (A) and $\mathrm{CN}_{\mathrm{X}-\mathrm{I}}(\mathrm{B})$ from EXAFS simulations as a 771 function of I content in mol.\%. The data are reported for Ca-I and Na-I and for ISG and NH 772 glass compositions. The error bars on each point is determined from the EXAFS fitting 773 results.

774 Figure 7: Change in the I CN as a function of $r_{X-I}$ in $\AA$. Data are obtained from EXAFS 775 simulations of the I-bearing studied glasses (ISG and $\mathrm{NH}$ ) and are compared to the data 776 obtained by McKeown et al. [11]. The values for crystalline compounds are also shown. 